University of Nebraska - Lincoln

DigitalCommons@University of Nebraska - Lincoln

\title{
Event-Based Data Collection for Generating Actuated Controller Performance Measures
}

\author{
Edward J. Smaglik \\ Purdue University \\ Anuj Sharma \\ University of Nebraska - Lincoln, anujs@iastate.edu \\ Darcy M. Bullock \\ Indiana University - Purdue University - Fort Wayne, darcy@purdue.edu \\ James R. Sturdevant \\ Indiana Depatment of Transportation \\ Gary Duncan \\ Econolite Control Products
}

Follow this and additional works at: https://digitalcommons.unl.edu/civilengfacpub

Part of the Civil Engineering Commons

Smaglik, Edward J.; Sharma, Anuj; Bullock, Darcy M.; Sturdevant, James R.; and Duncan, Gary, "EventBased Data Collection for Generating Actuated Controller Performance Measures" (2007). Civil Engineering Faculty Publications. 21.

https://digitalcommons.unl.edu/civilengfacpub/21

This Article is brought to you for free and open access by the Civil Engineering at DigitalCommons@University of Nebraska - Lincoln. It has been accepted for inclusion in Civil Engineering Faculty Publications by an authorized administrator of DigitalCommons@University of Nebraska - Lincoln. 


\title{
Event-Based Data Collection for Generating Actuated Controller Performance Measures
}

\author{
Edward J. Smaglik ${ }^{1}$, Anuj Sharma ${ }^{1}$, Darcy M. Bullock ${ }^{1,{ }^{*}}$, James R. Sturdevant ${ }^{2}$ and Gary Duncan ${ }^{3}$ \\ ${ }^{1}$ School of Civil Engineering, Purdue University, ${ }^{2}$ Division of Traffic Control Systems, \\ Indiana Department of Transportation, ${ }^{3}$ Econolite Control Products, *darcy@purdue.edu
}

Cycle-by-cycle data have been shown to be effective in the analysis of a signalized intersection with measures of effectiveness such as volume-to-capacity ratios, arrival type, and average vehicular delay. Currently, actuated traffic controllers are unable to store vehicle counts and vehicle occupancy in cycle-by-cycle bins, requiring extra equipment and personnel to collect data in these bins. The objective of this research was to develop an integrated general purpose data collection module that time stamps detector and phase state changes within a National Electrical Manufacturers Association actuated traffic signal controller and uses those data to provide quantitative graphs to assess arterial progression, phase capacity utilization, movement delay, and served volumes on a cycle-by-cycle basis. Given that the United States recently received a grade of 61 of 100 on the National Traffic Signal Report Card, it is particularly important that procedures such as these be used to provide performance measures over extended periods so agencies have cost-effective mechanisms for assessing and priorityranking signal timing efforts.

Data collection methods used by the Highway Capacity Manual (HCM) (1) are employed worldwide for quantifying the performance of signal systems. Those methods are oriented toward adjusting hourly volumes-to peak 15-minute flow rates for analysis and work very well with manually-collected data. However, it is not feasible for agencies to schedule manual data collection activities for extended periods or during unusual periods such as evening school events or weekend peaks at shopping malls. Consequently, it is desirable to have signal systems collect their own data for assessing their performance through an integrated general purpose data collection module within the controller.

However, obtaining meaningful real-time performance data from signalized intersections has historically been challenging for two reasons:

- Typical stop-bar loop detectors provide good occupancy data but poor flow rate information (2).

- Data are typically recorded by controllers on an hourly or 15-minute basis.

However, in the case of modern traffic controllers, phase splits and phase lengths vary cycle by cycle and the arbitrary binning in 5-, 15-, or 60-minute basis the controller does not permit tabulating data on a cycle-by-cycle basis. Consequently, it is impossible to evaluate theperformance of individual phases and splits on a cycle-by-cycle basis.

For example, Figure 1 is a 24-hour plot of occupancy binned into 15-minute intervals, downloaded from an actuated controller. The occupancy of 12 separate detectors is plotted versus time. A similar plot can also be generated from count data. From this graph, it is clear that the intersection is reasonably busy from 5:00 a.m. to 10:00 p.m. Some detectors (for example, Detector 6) have pronounced morning and afternoon peaks. However, the following information is not at all clear from these graphs:

- How well progression is working in each direction,

- If there are any split failures that need attention, and

- The average delay experienced by motorists.

\section{LITERATURE REVIEW}

The North Carolina Department of Transportation found that one of the challenges of pulling useful data from loop detectors is producing it in a format that is useful to planners, designers, and other end users (3). To process data from its freeway sensors, the California Department of Transportation developed a system that collects loop detector data in real time and returns it in a format specified by the user (4). A system by the name of COMPASS was implemented in some areas of Toronto, Canada, for collecting information from SCOOT-controlled arterials and making it available to users. Data are collected in 20 -second intervals and aggregated into time static intervals $(5,15$, and 60 minutes; daily and monthly) and archived on a compact disc $(3,5)$. The Texas Transportation Institute recently completed research that developed a listof performance measures that could be collected within the limitations of existing detection systems and then developed a prototype system to automatically collect these data. Performance measures computed by this system include cycle time; time to service; queue service time; duration of the green, yellow, all-red, and red interval for each phase; number of vehicles entering the intersection during each interval; yellow and all-red violation rates; and phase failure rates. Collection of these data required the addition of a black box to the cabinet for data collection as well as count detectors placed in front of the stop bar (6). 


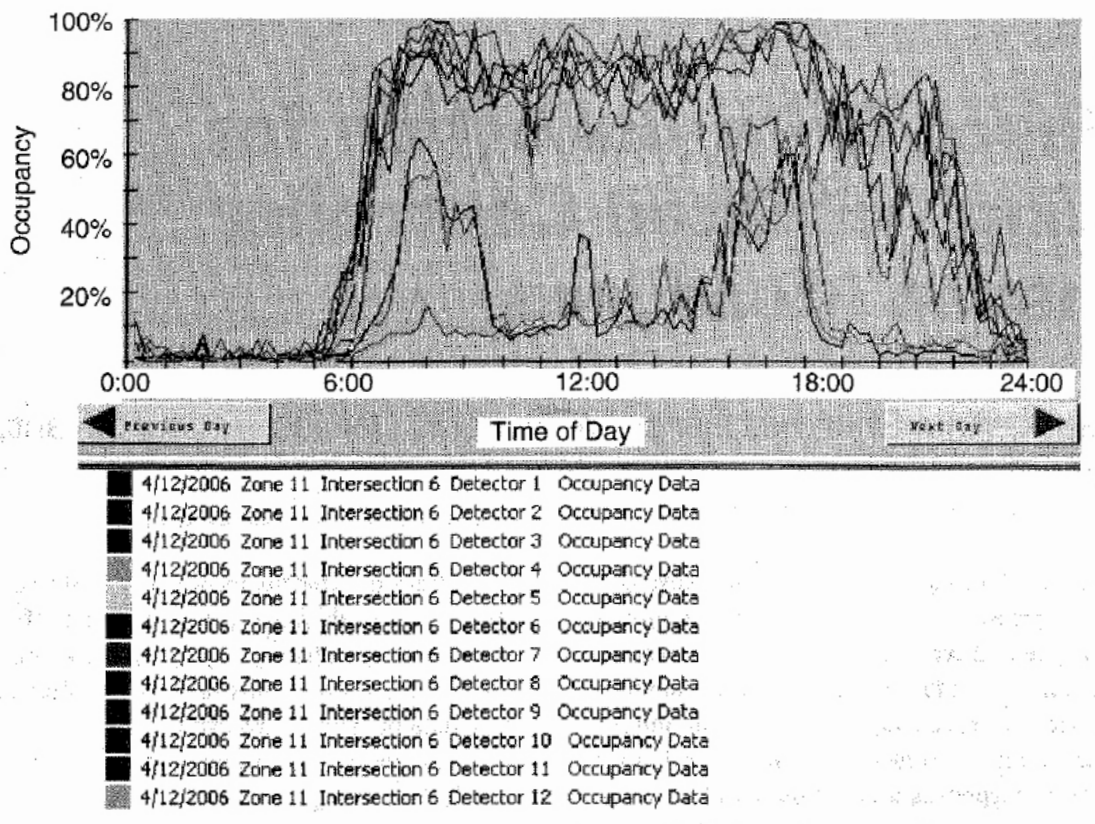

FIGURE 1 Detector data binned in static (15-min) intervals.

Even though data aggregation from some of these efforts is user specified, it has required additional hardware to obtain useful information from vehicle detector data. The research documented here describes an integrated general purpose data collection module that time-stamps detector and phase state changes within a National Electrical Manufacturers Association (NEMA) actuated traffic signal controller. The data collected are then used to provide quantitative graphs that assess progression and intersection delay.

\section{CONTROLLER ENHANCEMENT}

To make it possible to produce data easily for measures of effectiveness (MOEs), it is desirable to collect event-based data directly in the controller. In a cooperative effort involving Econolite Control Products, Inc., the Indiana Department of Transportation (INDOT), and Purdue University, the Econolite ASC/ 3 controller software was enhanced to include a data logger to collect time-stamped phase and detector state changes. Elements of the data logger include

- Time-stamped state changes of phases in use (1 to 16$)$ and detectors in use (1 to 64) are stored in binary format on the ASC/3 controller in hourly data files.

- Data are retrieved from the controller by using a transmission control protocol/Internet protocol network connection, with the controller serving as a file transfer protocol (FTP) server.

- Once downloaded from the controller, a Windows-based wizard is used to convert the binary data files into comma-separated-value (CSV) files for use in producing the appropriate reports.

Figure 2 shows the FTP access of the controller log data with Microsoft Windows Internet Explorer. During busy periods, the compressed data logs for 1 hour are approximately $90 \mathrm{~kb}$ (around 5:00 p.m.), but the compressed logs are only about 7 $\mathrm{kb}$ (around 2:00 a.m.) during periods with lighter traffic and fewer cycles. These compressed files can be downloaded and converted into CSV files to produce performance measures such as arrival type, delay, volume-to-capacity $(v / c)$ ratios, or served volumes.

\section{CYCLE-BY-CYCLE DATA COLLECTION}

Although there are a variety of ways that the data can be aggregated, cycle-by-cycle tabulation has been shown to be an effective method of categorizing data for adaptive control, offset tuning, and other signaltiming measures (7-11). It can also be used to produce MOEs such as arrival type, average vehicular delay, $v / c$ ratios, and equivalent hourly volume. Figure 3 illustrates the cycle-by-cycle tabulation boundaries in relation to the percentage of vehicles arriving during the green interval, where each black circle represents an actuation of a setback detector. With cycle-by-cycle analysis, the performance during each cycle can be quantified. For example, if $\mathrm{C} 1, \mathrm{C} 2$, and C3 were placed into one large bin, the proportion arriving on the green would be $53 \%$, and the individual values of $20 \%, 60 \%$, and $80 \%$ would be overlooked.

\section{DESCRIPTION OF TEST BED INTERSECTION}

An ASC/3 controller with enhanced software was implemented at the INDOT intersection test bed in Noblesville, Indiana. This site is instrumented with 12 data collection units; the MOE plots shown in this paper use data collected by the ASC/ 3 controller. Figure 4 is an aerial view of the test bed intersection and surrounding area.

Distance to the nearest signalized intersection in each direction is shown in Figure 4 as well as the location of the setback detectors on both the northbound and southbound approaches. The section of roadway immediately north of the intersection experiences an annual average daily traffic (AADT) of 24,080 vehicles, and the section immediately west experiences an AADT of 20,830 vehicles. The intersection is controlled by an 


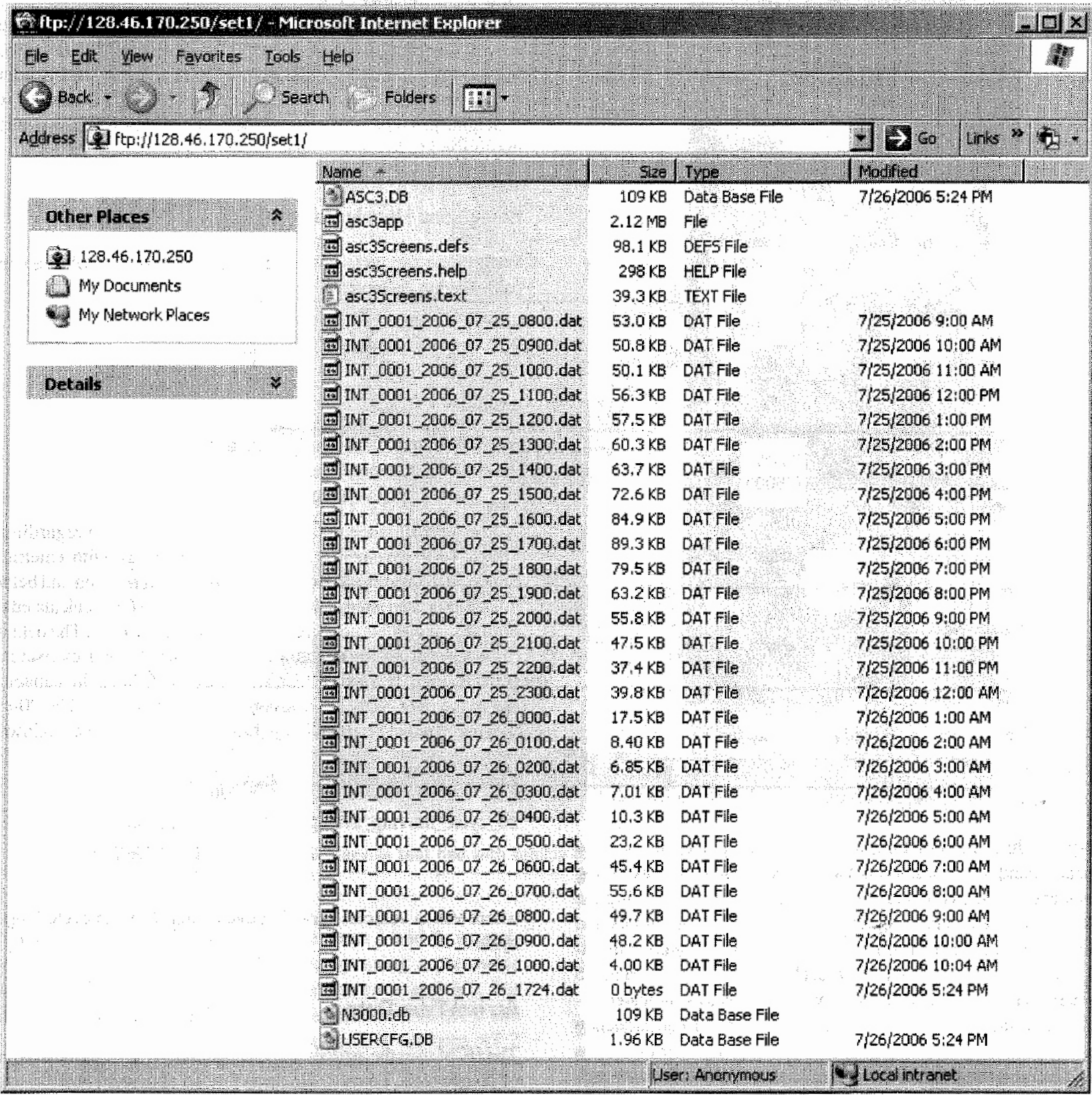

FIGURE 2 FTP access of collected data.

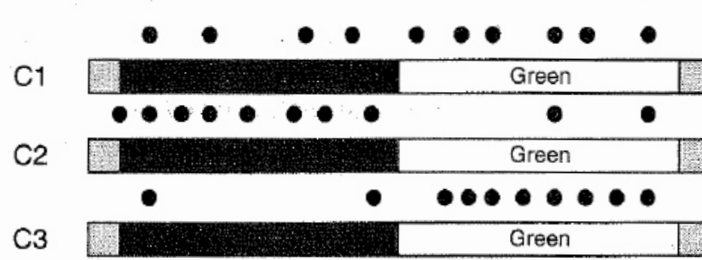

Percent Arrival on Green

$60 \%$

$20 \%$

$80 \%$

FIGURE 3 Cycle-by-cycle data collection. 


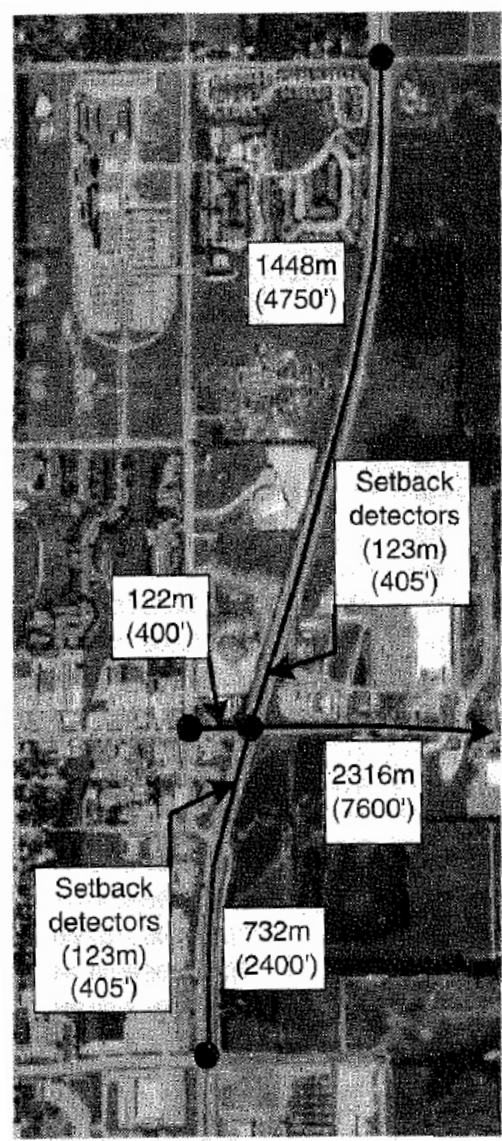

FIGURE 4 Aerial view of Noblesville test bed and adjacent intersections.

actuated controller and operates a typical eight-phase dualring structure, with coordination in the northbound and southbound directions during the a.m. peak and p.m. peak timing periods and in the eastbound and westbound directions during the midday and off-peak timing periods. The northbound and southbound approaches are high-speed approaches $(88 \mathrm{kph}$, or $55 \mathrm{mph}$ ) with set-back detectors located 123 meters (405 feet) back from the stop bar. Figure 5 is an aerial view of the test bed with vehicle detectors indicated.

All loops shown in Figure 5 are 6-foot-round preformed inductive loops. Stop bar loops shown in Figure 5 are tied together in various series configurations (series loops are separated by 9 feet), and each lane operates on an individual amplifier and lead-in cable. All loop amplifiers assigned to stop bar loops have both a presence and a count output. All setback loops also operate on a lane-by-lane basis. On the northbound approach, which has two sets of setback loops in each lane, the loops in each lane operate independently of each other and on a laneby-Iane basis. Intersection operation is driven by the presence output of both stop bar and setback detectors.

\section{CONTROLLER IMPLEMENTATION}

On July 24, 2006, the ASC/3 controller with enhanced software was implemented at the test bed. During the study period, while data were collected in the controller, independent data collection units and video were also used at the intersection to allow verification of the data collected by the controller. After approximately 40 hours of operation, data were retrieved from the controller, and performance plots were prepared showing equivalent hourly volume served, progression quality, vehicular delay, and $v / c$ ratios. To verify the accuracy of the data logger in the ASC/3 controller, all data collected by the controller were compared with data collected independently by the data collection units. Data from the ASC/3 controller were benchmarked against data from the data collection units to validate the new ASC/3 controller data collection system.

\section{Equivalent Hourly Volume}

With cycle-by-cycle data, the equivalent hourly volume can be calculated as follows:

$$
\mathrm{EHV}=\left(\frac{3,600}{C}\right)+v
$$

where

$$
\begin{aligned}
& \mathrm{EHV}=\text { equivalent hourly volume, } \\
& \mathrm{C} \quad=\text { cycle length, and } \\
& v \quad=\text { served volume. }
\end{aligned}
$$

This performance measure provides information regarding the volume on a movement at any point during the day, with a metric that can be easily compared from intersection to intersection and between movements at an intersection. Figure 6 shows the EHV calculated from cycle-by-cycle data collected by the ASC/3 controller The data collected during undersaturated conditions. During oversaturated periods, the EHV will effectively max out toward the capacity of the movement, since it is essentially served volume. The 20-cycle moving average presented in Figure 6 was calculated as follows:

$$
\text { 20_cycle_moving_average }=\left(\frac{\sum_{i}^{20} \mathrm{veh}_{i}}{\sum_{1}^{20} C_{i}}\right) * 3,600
$$

where veh is vehicles served in cycle $i$ and $C$ is the cycle length of cycle $i$.

\section{Arrival-Type Data}

The HCM uses the arrival-type (AT) parameter to describe the quality of progression. To calculate the AT of all approach vehicle arrival must be collected and binned into cycle-by-cycle intervals as shown in Figure 3, along with collection of green durations and cycle lengths. A vehicle arrival is defined as the time when the vehicle passes over the advance detectors shown in Figure 4. Vehicle arrivals for calculating AT data must come from setback detectors, since vehicle arrivals cannot be collected from stop bar detectors once the first vehicle arrives at the stop bar. Vehicle arrival data are then input into the HCM equation for platoon ratio and assigned an AT ranging from 1 $\left(R_{p}\right.$ less than 0.50$)$ to $6\left(R_{p}\right.$ greater than 2.00$)$ by using HCM Exhibit 15-4 $(1,12)$

$$
R_{p}=P\left(\frac{C}{g}\right)
$$

where $P$ is the percent of vehicles arriving on green and $g$ is the length of the green indication. 


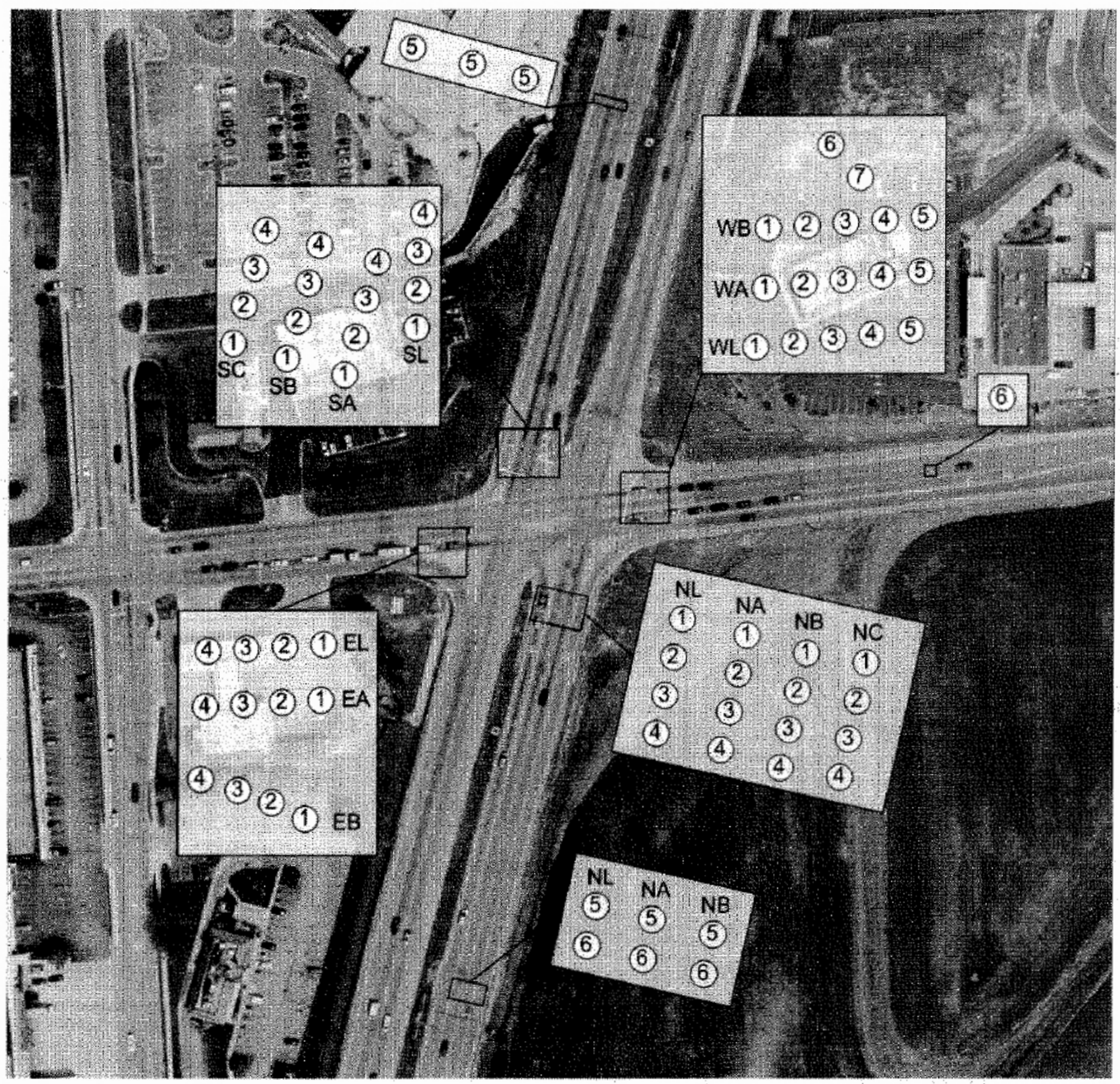

FIGURE 5 Aerial view of Noblesville test bed with vehicle detector information.

In addition to classification of AT between 1 and 6, an estimated continuous AT can be calculated by using a piecewise continuous relationship between the platoon ratio and AT. For example, a platoon ratio of 0.5 is the threshold between AT 1 and AT 2, and a platoon ratio of 0.85 is the threshold between AT 2 and AT 3. Linear interpolation is used between these thresholds to provide a continuous estimate of AT based on the platoon ratio. Both the classified AT and estimated continuous AT are shown in Figure 7. Cycles in which arrivals were queued over the upstream detector (Figure 4) are shown as a triangle, diamond, or star in Figure 7. Calculated ATs were averaged over a 20-cycle moving average to remove noise from the data. The value of 20 cycles was chosen for smoothing purposes, removing enough noise to allow for easier examination of the data without removal of relevant fluctuations.

The vertical lines shown in Figure 7 represent changes in time-of-day plans. This plot can be quickly examined to assess the progression performance of an intersection and investigate the impact of split and offset changes as these plans change throughout the day. The data presented in Figure 7 were collected during undersaturated conditions. As the study movement becomes oversaturated, this methodology will underesti- mate vehicle arrivals red, since the queue will likely pass well beyond the setback detection area.

Delay Data

The same event data used to assess vehicle progression can be used to estimate vehicular delay. With arrival and departure profiles, average vehicular delay per cycle can be calculated $(13,14)$. Figure $8 \mathrm{a}$ and $\mathrm{b}$ shows the queue profiles for $\mathrm{C} 2$ and C3 in Figure 3, representing poor progression and good progression, respectively. The queue profile represents the vehicle delay during each cycle and is calculated on the basis of both the arrival profile and the departure profile. The arrival profile is based on vehicle arrivals over setback detectors (Figures 4 and 5), whereas the departure profile is based on the saturation flow rate of vehicle departures over stop bar detectors (Figure 5). The area under the queue profile is the average vehicular delay during the cycle. Figure $8 \mathrm{c}$ is a 24 -hour plot of average vehicular delay on a cycle-by-cycle basis, plotted by using a 20 -cycle moving average. Obviously, if traffic queues.over the advance detector during oversaturated conditions, there can be significant errors in estimated delay because the arrival flows must be estimated, not observed. 


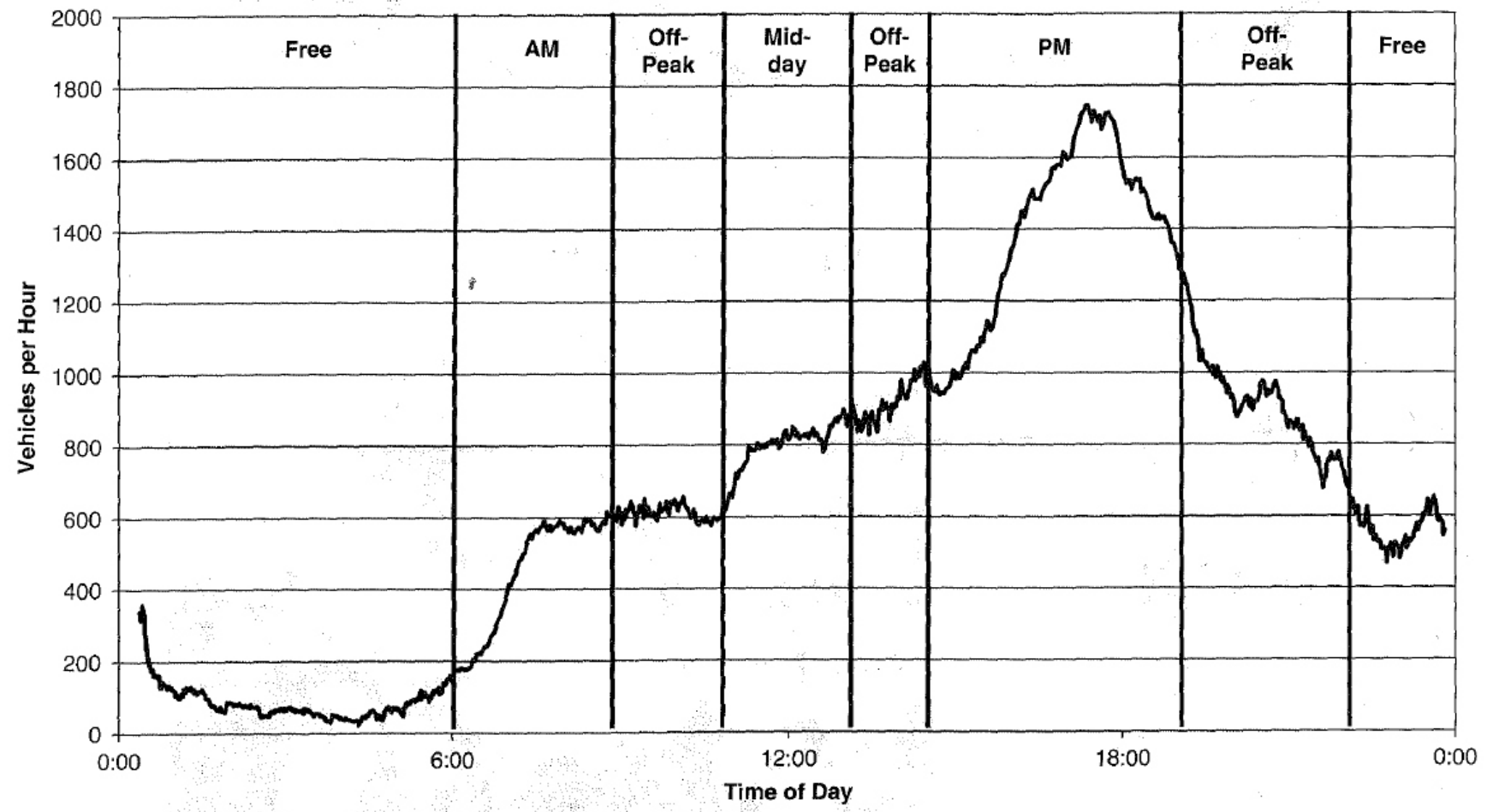

FIGURE 6 EHV, 20-cycle moving average, northbound, Tuesday, July 25, 2006.

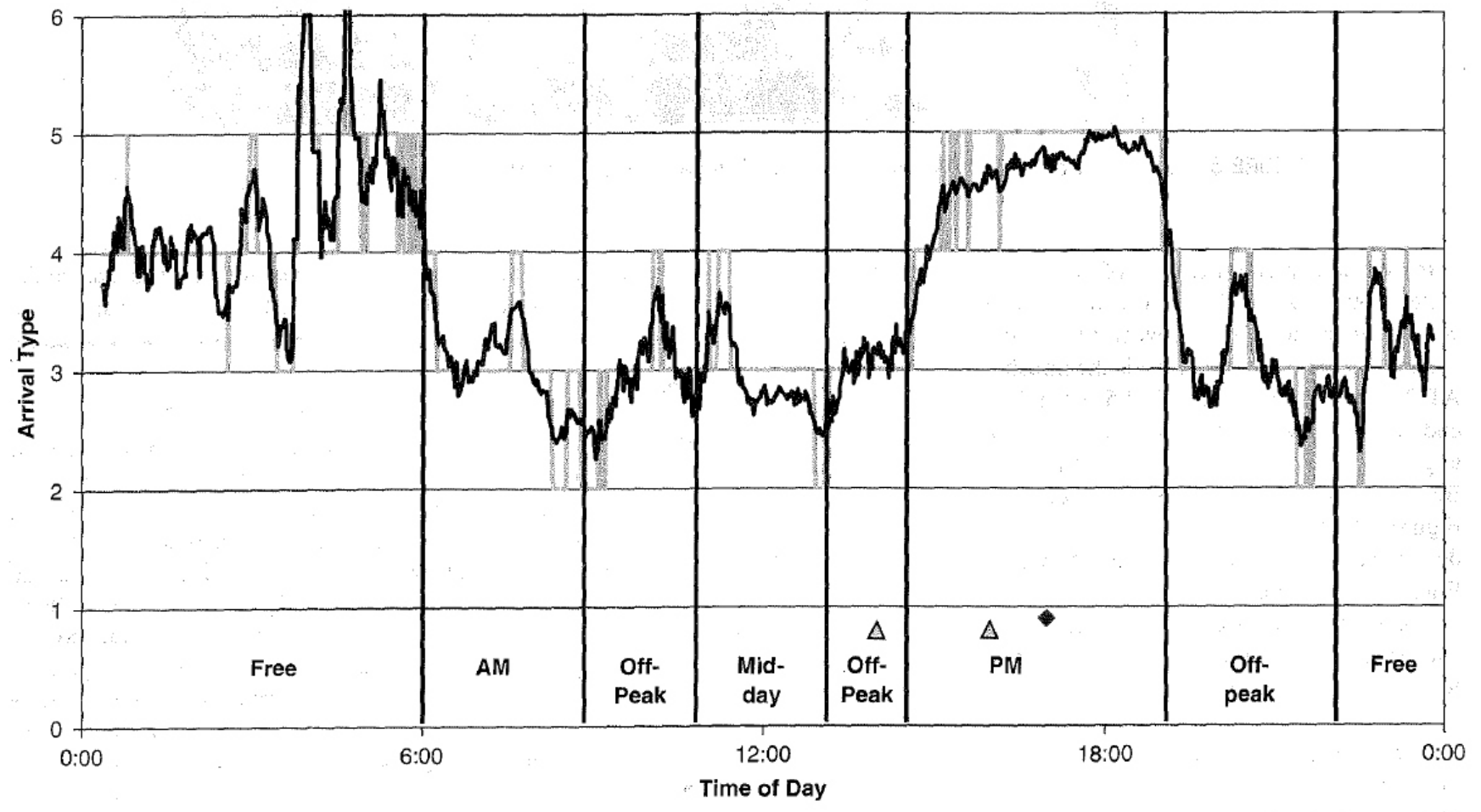

Arrival Type $\triangle$ Lane A Lane B $*$ Lane C - Estimated Continuous Arrival Type

FIGURE 7 AT values, 20-cycle moving average، ASC/3 data, northbound, Tuesday, July 25, 2006. 


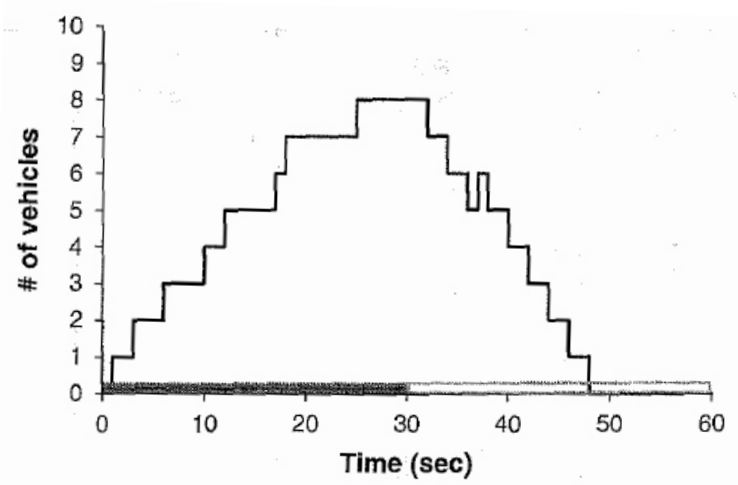

(a)

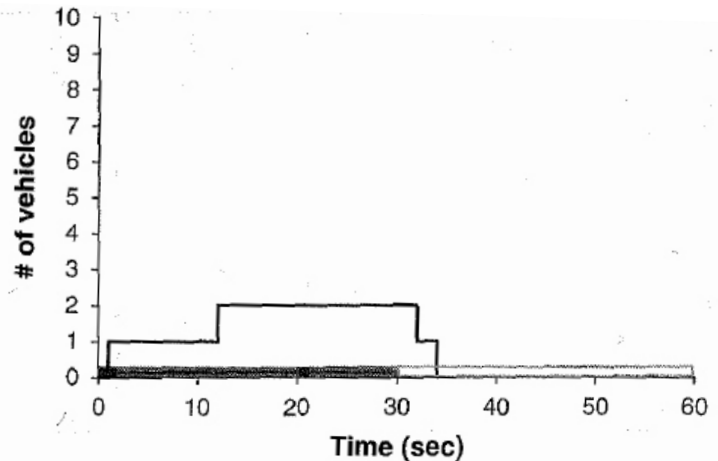

(b)

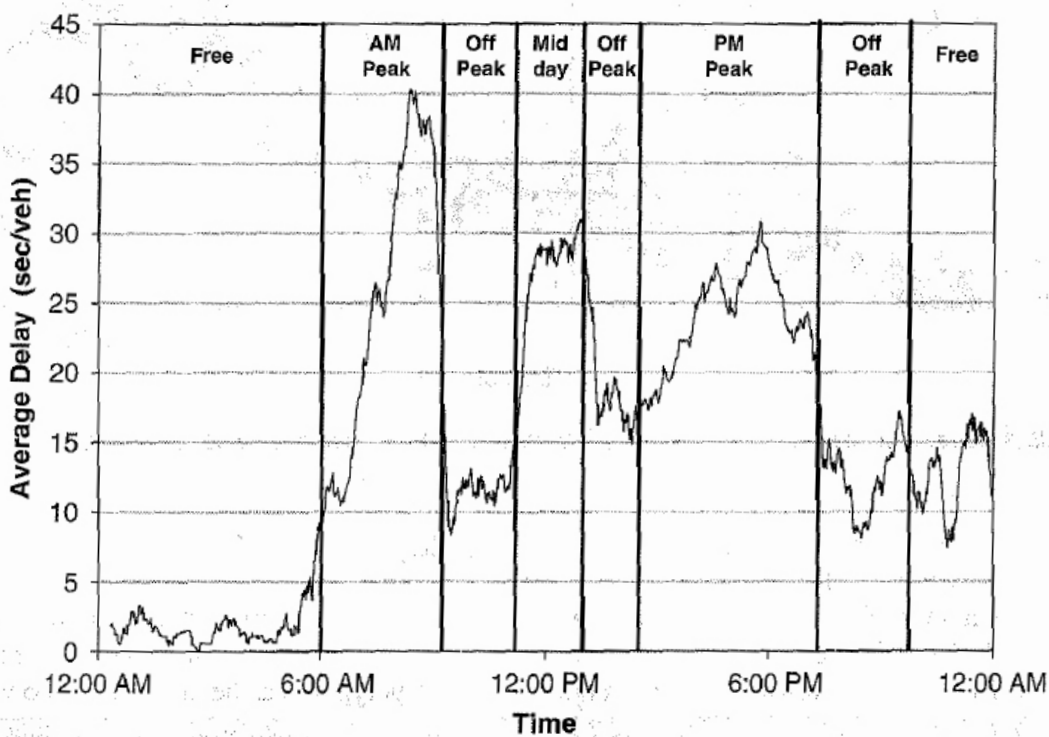

(c)

FIGURE 8 Delay plots: $(a)$ queue profile for $C 2$, poor progression, $(b)$ queue profile for $C 3$, good progression, and $[c]$ average vehicular delay, 20-cycle moving average, ASC/3 data, northbound through movement, Tuesday, July 25, 2006.

\section{Volume-to-Capacity Ratio}

With the vehicle departures from stop bar count detectors (Figure 5) binned on a cycle-by-cycle basis, phase indication length, and cycle length, an estimated vic ratio can be calculated for each individual green indication as follows (1):

$$
\left(\frac{v}{c}\right)_{l}=\frac{q_{g}}{\left[s_{l} *\left(\frac{g_{l}}{C}\right)\right]}=\frac{\left(v_{l} * C\right)}{\left(s_{l} * g_{l}\right)}
$$

where

$V_{I}=$ served flow rate for lane group $l$,

$C_{I}=$ capacity of lane group $l$,

$q_{g}=$ flow rate observed for green phase,

$S_{I}=$ observed lane saturation flow rate,

$C=$ cycle length, and

$g_{l} \quad=$ length of green indication for movement $l$.

Figure 9 plots each $v / c$ ratio over a 24-hour period for Phase 2 (northbound approach) at the Noblesville test bed. Not sur- prisingly, around 5:00 p.m. the flow rate (Figure 6) and delay (Figure 8) peak for the p.m. peak timing period. However, from examining Figure 7, which quantitatively documents progression quality, the quality of the progression is excellent in the subject direction.

The few points above 1.0 in Figure 9 suggest that there are a couple of cycles in which there may be a split failure. If the $v / c$ plots for competing phases were compared, these graphs could be used for reallocating split times (11). The data shown in Figure 9 were collected during undersaturated conditions. During oversaturated periods, the $v / c$ will effectively hover around 1.0, since the volume component used for this calculation is served volume.

\section{DATA COLLECTION OVER TIME}

In addition to MOEs of current traffic data, trends in data can also be tracked over time. Figure 10 tracks EHV and AT between two dates approximately one year apart. On August 9, 2005, EHV and AT were calculated from cycle-by-cycle data collected by the data collection units at the Noblesville test bed. Those data are compared with those collected by the ASC/3 controller on July 25, 2006. 


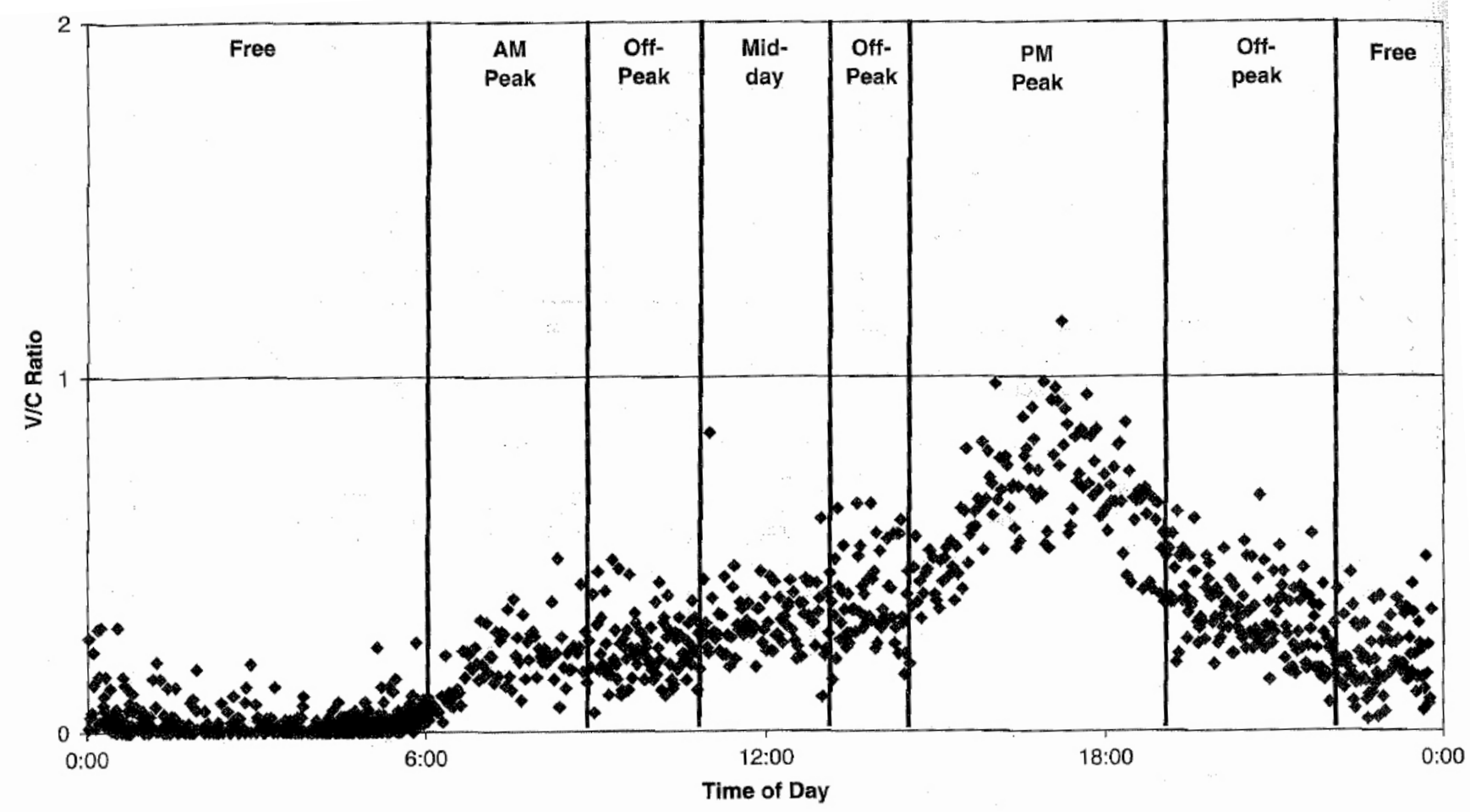

FIGUAE 9 Cycle-by-gycle data collection, v/c ratio plot from ASC/3 data, Phase 2, Noblesville test bed, Tuesday, July $25,2006$.

Figure 10a shows EHV, and Figure 10b shows AT. One item to note is that in 2005, the p.m. peak timing plan went into effect at 1:00 p.m. and timed until 7:00 p.m. In 2006, the off-peak timing plan was in effect from 1:00 p.m. to 2:30 p.m., followed by the p.m. peak timing plan from 2:30 p.m. to 7:00 p.m. The impact of this change in plan time can be seen by observing the shift in the AT around this time in Figure 10b.

\section{DETECTION REQUIREMENTS FOR DATA COLLECTION}

The plots developed for this research require vehicle counts; however, desired detection placement and installation vary depending on the MOE.

\section{EHV and $v / c$ Ratio}

Vehicle counts can be collected from either setback or stop bar detectors. Setback detectors can operate in either presence or count mode, provided that the detection zone is small ( $\sim 6$ feet). If operating in the presence mode,detectors can be operated on a movement basis; however, some data will be lost when traffic queues over the setback detection area. If counts are collected at the stop bar, each lane must be on a separate channel, equipped with a count amplifier.

\section{Arrival Type}

Vehicle counts must be collected from setback detectors, since stop bar detectors are unable to mark the arrival of vehicles after the first vehicle enters the detection zone. The same issues discussed for EHV for setback detectors apply for AT as well.
Delay

Estimation of delay is essentially more extensive processing of the advance detector information (used for measuring AT), so the queue delay polygons can be modeled as shown in Figure 5a. The data collection requirements for delay estimation are identical to those used for AT estimation.

\section{CONCLUSION}

An integrated general purpose data collection module is described that time-stamps detector and phase state changes within a NEMA actuated traffic signal controller and then uses those data to provide quantitative graphs that assess progression and intersection delay. With the detection requirements and procedures described here, performance measures can be collected over extended periods to provide agencies with costeffective mechanisms for assessing and priority-ranking signal timing efforts. Although the compilation of the plots in this paper used spreadsheets and other analysis tools, the ultimate goal is to integrate this functionality into vendor-supplied closed-loop system management software. Ultimately it would be desirable to have the industry standardize on the definitions of these MOEs as well as the methods by which they are calculated.

\section{ACKNOWLEDGMENTS}

This work was supported by the Joint Transportation Research Program administered by the Indiana Department of Transportation and Purdue University. The controller hardware used in this research was the ASC/ 3 controller manufactured by Econolite Control Products, Inc. 


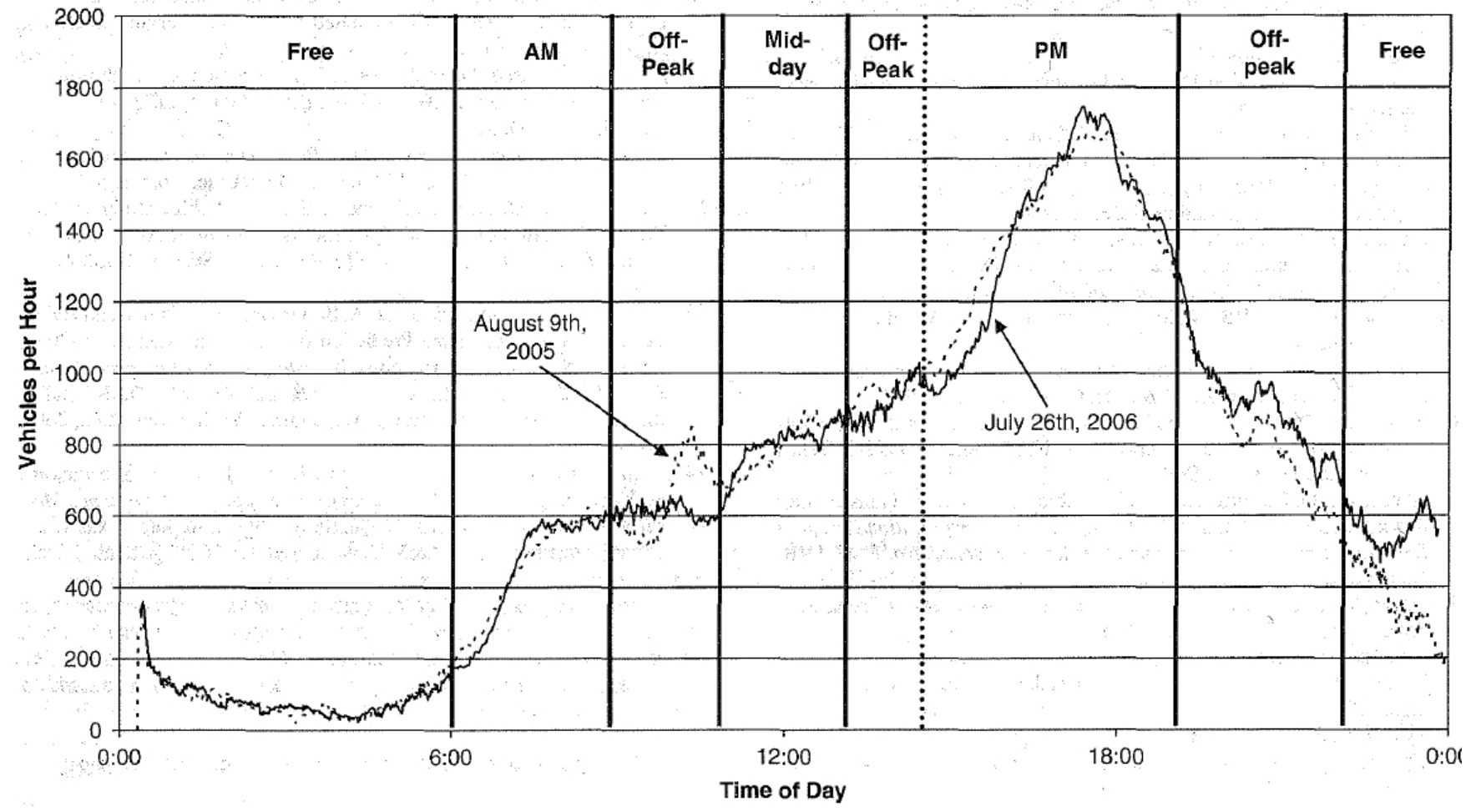

(a)

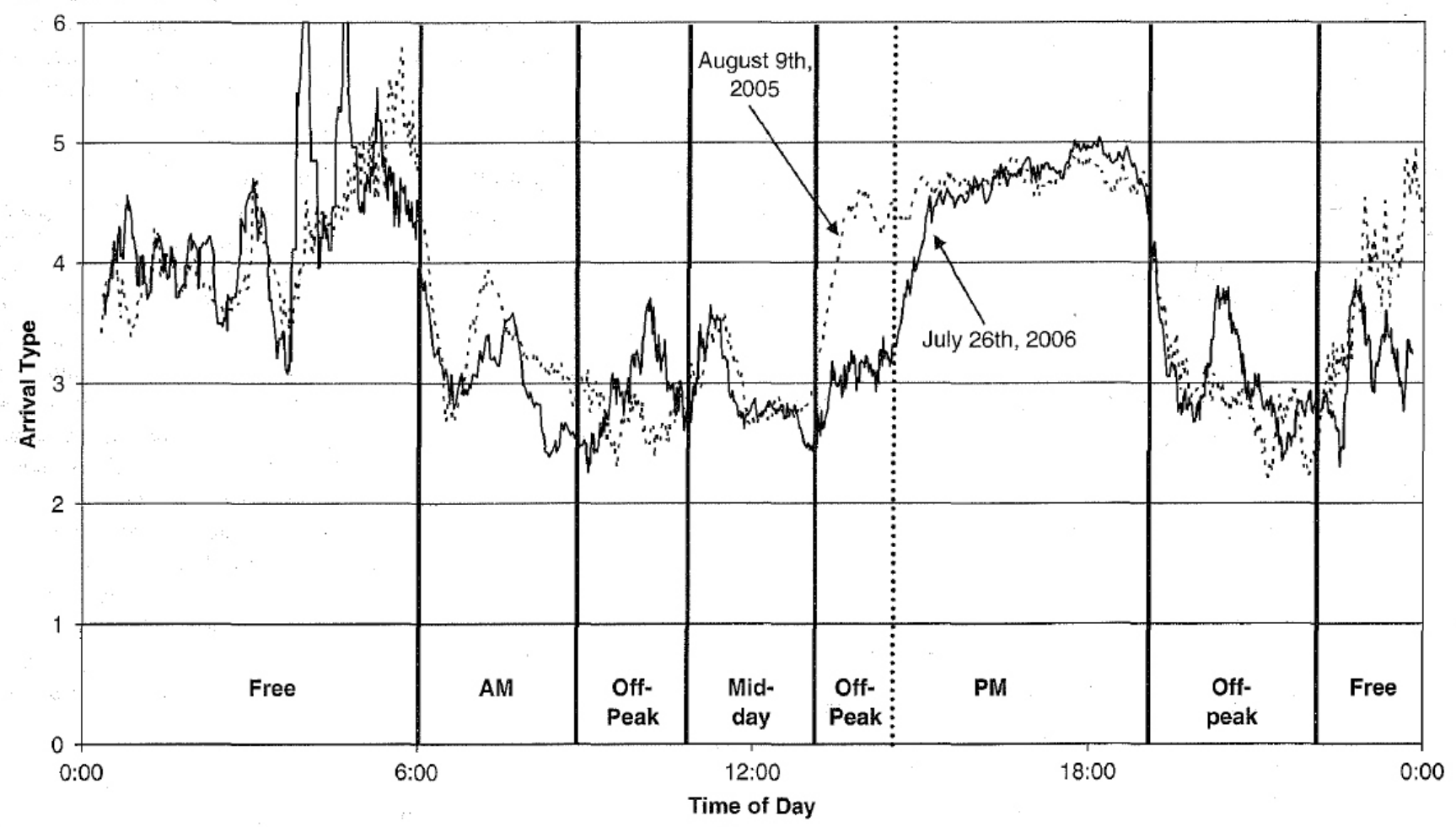

(b)

FIGURE 10 Tracking MOEs over time, August 9, 2005, and July 25, 2006: (a) EHV, 20-cycle moving average and (b) AT, 20-cycle moving average. 


\section{REFERENCES}

1. Highway Capacity Manual. 2000. Transportation Research Board, National Research Council, Washington, D.C.

2. Smaglik, E. J. Enhanced Tactical and Strategic Control Methods for Traffic Signal Operation. 2005. Doctoral dissertation. Purdue University, West Lafayette, Indiana.

3. Milazzo, J., R. S. Foyle, T. Rhoulac, K. Tanaka, C. Thompson, T. Delk, B. Forbis, S. Hill and S. McDonald. Overcoming Obstacles to the Use of Traffic Signal Detector Data for Traffic Forecasting. 2001. North Carolina Department of Transportation, Raleigh.

4. Chen, C., K. Petty, A. Skabardonis, P. Varaiya and Z. Jia. Freeway Performance Measurement System: Mining Loop Detector Data. 2001. Transportation Research Record: Journal of the Transportation Research Board, No. 1748: 96-102.

5. ITS Data Archiving: Case Study Analyses of San Antonio TransGuide Data. 1999. Texas Transportation Institute, Texas A \& M University System, College Station.

6. Balke, K. N., H. Charara and R. Parker. Development of a Traffic Signal Performance Measurement System. May 2005. TTI Report 0-04422-2. Texas Transportation Institute, College Station.

7. Abbas, M., D. Bullock and L. Head. Real-Time Offset Transitioning Algorithm for Coordinating Traffic Signals. 2001. Transportation Research Record: Journal of the Transportation Research Board, No. 1748: 26-39.

8. Abbas, M., D. Bullock and A. Rhodes. Comparative Study of Theoretical, Simulation, and Field Platoon Data. 2001. Traffic Engineering and Control, Vol. 42, No.7.

9. Luyanda, F., D. Gettman, S. Shelby, L. Head, D. Bullock and P. Mirchandani. ACS-Lite Algorithmic Architecture: Applying Adaptive Control System Technology to Closed-Loop Traffic Signal Control Systems. 2004. Transportation Research Record: Journal of the Transpor- tation Research Board, No. 1856: 175-184.

10. Smaglik, E. J., D. M. Bullock and T. Urbanik Evaluation of Laneby Lane Vehicle Detection for Actuated Controllers Serving Multilane Approaches. 2005. Transportation Research Record: Journal ofthe Transportation Research Board, No. 1925: 123-133.

11. Smaglik, E. J., D. M. Bullock, and T. Urbanik II. Adaptive Split Control Using Enhanced Detector Data. 2005. Proceedings, ITE International Annual Meeting and Exhibit, Paper AB05H-11, Melbourne, Australia.

12. Smaglik, E. J., D. M. Bullock and A. Sharma. A Pilot Study on RealTime Calculation of Arrival Type for Assessment of Arterial Performance. July 2007. Journal of Transportation Engineering, Vol. 133, No.7.

13. Sharma, A., D. M. Bullock and J. A. Bonneson. Input-Output and Hybrid Techniques for Real-Time Prediction of Delay and Maximum Queue Length at Signalized Intersections. 2007. Transportation Research Record: Journal of the Transportation Research Board, No. 2035: 69-80.

14. Bonneson J., D. Bullock, P. Koonce, D. Middleton, A. Sharma and M. Vandehay. Review of Techniques for Urban Street Performance Measurement. 2006. NCHRP Project 3-79, Quarterly Progress Report. Texas Transportation Institute, Texas A \& M University System, College Station.

The contents of this paper reflect the views of the authors, who are responsible for the facts and the accuracy of the data presented, and do not necessarily reflect the official views or policies of the Federal Highway Administration and the Indiana Department of Transportation, nor do the contents constitute a standard, specification, or regulation.

The Traffic Signal Systems Committee sponsored publication of this paper. 